\title{
Immunocytochemical Labelling of Bacteroides nodosus Pili Using an Immunogold Technique
}

\author{
By JULIAN E. BEESLEY, ${ }^{*}$ SARAH E. J. DAY, MARK P. BETTS \\ AND C. MICHAEL THORLEY \\ Wellcome Research Laboratories, Beckenham, Kent BR3 3BS, UK
}

(Received 12 December 1983)

\begin{abstract}
An immunogold labelling technique was used to label the pili of the bacterium Bacteroides nodosus. The labelling was distinct and highly specific, and individual pili could be recognised beneath the gold probe. The labelling of somatic antigens could be distinguished from that of pilus antigens. Furthermore, labelling of fragments of cytoplasm released by cell lysis and trapped in the pili could be distinguished from pilus labelling. An antiserum that had been raised against strain 80200 (serotype N) labelled pili of strain 215 (serotype B). Double labelling experiments with this antiserum and the antiserum against strain 215 (serotype B) showed that both antisera label the same pili bundles. The ease of detection of the immunocytochemical reaction should enable this technique to be used as a routine screen for pilus antigens. It also possesses the potential for much wider applications for immunolabelling other antigens, such as viruses, that can be obtained in suspension.
\end{abstract}

\section{INTRODUCTION}

The pili of Bacteroides nodosus are important immunogens in the elicitation of protection of sheep against footrot (Stewart, 1975, 1978; Every \& Skerman, 1982, 1983; Stewart et al., 1982). Immunocytochemical examinations of the pili are thus major considerations in the study of $B$. nodosus.

Antibody molecules or antibody molecules tagged with a ferritin probe can be visualized on pili in the electron microscope by negative staining (Walker et al., 1973; Short et al., 1976). It is relatively easy to visualize large numbers of antibody molecules on a pilus by these techniques, but as the concentration of antibody decreases it becomes increasingly difficult to distinguish specific pilus labelling from background debris. Furthermore, these techniques can detect only one antigen in each preparation and depend almost entirely on consistently high quality negative stain preparations.

Antibody attached to antigen can be located also by the colloidal gold techniques. In these techniques gold spheres are coupled either to Protein A (Roth et al., 1978) or to antibody specific for the species in which the primary antibody was raised (de Mey et al., 1981). These immunocytochemical probes can then be reacted with the primary antibody. Also, gold probes of different sizes can be used sequentially for labelling two antibodies in one preparation (e.g. Geuze et al., 1981; Bendayan, 1982).

This report describes the application of the immunogold technique to immunocytochemical studies of $B$. nodosus pili preparations and considers its value as a routine screening technique.

\section{METHODS}

Bacterial cultures. The strains of Bacteroides nodosus used in this study were 148 (serotype H), 215 (serotype B), 217 (serotype C), 1045 (serotype F), 175 (serotype G), isolated from footrot in sheep in Australia and 80116 (serotype K) and 80200 (presumptive serotype N) isolated from footrot in sheep in the UK. 
The cultures were grown in broth containing $3 \%(w / v)$ bacteriological peptone (Oxoid), $1.5 \%(w / v)$ tryptone (Oxoid) and $1 \%(\mathrm{w} / \mathrm{v})$ liver digest (Oxoid), pH 7.9 at $37^{\circ} \mathrm{C}$ (Thorley \& Egerton, 1981) to the late exponential phase, and fixed with $0.5 \%(\mathrm{v} / \mathrm{v})$ formaldehyde.

Antiserum production. Antiserum against bacterial strains 148 (serotype H), 215 (serotype B), 1045 (serotype F) and 80200 (serotype $\mathrm{N}$ ) were prepared as follows. Formaldehyde-inactivated cultures of $B$. nodosus were concentrated by isoelectric precipitation at $\mathrm{pH} 4 \cdot 7$. The cell concentrate was adsorbed onto Alhydrogel (Superfos, Denmark) to a final concentration of $20 \%(\mathrm{v} / \mathrm{v})$. Then $1 \%(\mathrm{v} / \mathrm{v})$ Tween 80 and $0.01 \%(\mathrm{w} / \mathrm{v})$ Thiomersal were added. Two parts of this were emulsified with three parts of mineral oil consisting of Marcol 52/Arlacel A(13) (90:10, $\mathbf{v} / \mathbf{v})$.

New Zealand White rabbits were injected subcutaneously with these preparations. At least two injections, each of $0.3 \mathrm{ml}$, were given at intervals of approximately six weeks. The rabbits were bled two to four weeks after the final injection.

Antiserum against strain 215 (serotype B) was absorbed with bacterial strains 80200 (serotype N), 80116 (serotype K), 217 (serotype C) and 175 (serotype G). Antiserum against strain 80200 (serotype N) was absorbed with bacterial strains 215 (serotype $B$ ) and 80116 (serotype $K$ ). The absorption was effected by mixing one volume of packed $B$. nodosus cells with two volumes of antiserum at $37^{\circ} \mathrm{C}$ for $45 \mathrm{~min}$. Our results show that two sequential absorptions were sufficient to remove antibody specific to the absorbing strains.

Immunocytochemical labelling. The bacteria were washed and resuspended in distilled water. Drops of this suspension were dried down onto $\mathbf{4 0 0}$ mesh carbon/Butvar-coated gold grids. The grids were incubated face down for $15 \mathrm{~min}$ on a suitable concentration of the appropriate antibody. They were washed for 3 min in running tap water before incubation for $1 \mathrm{~h}$ with $5 \mathrm{~nm}$ colloidal gold spheres coated with antibody against rabbit $\mathrm{IgG}$ (a gift from Dr J. de Mey, Janssen Pharmaceutica, NV, B-2340, Beerse, Belgium). The preparations were then negatively stained and examined in a Philips 300 transmission electron microscope.

Colloidal gold spheres, $20 \mathrm{~nm}$ diameter, coated with goat anti-rabbit IgG (also a gift from Dr J. de Mey) were used in conjunction with the $5 \mathrm{~nm}$ probe for double labelling experiments. In double labelling experiments the procedure was the following sequence: first antibody $(15 \mathrm{~min}) ; 5 \mathrm{~nm}$ gold probe (three sequential incubations of $1 \mathrm{~h}$ each ensured that this probe saturated all the Fc sites on the primary antibody); second antibody (15 min); $20 \mathrm{~nm}$ gold probe $(1 \mathrm{~h})$. Several control variations of this schedule were carried out as described below. (i) The second antibody was omitted to check that the $5 \mathrm{~nm}$ probe was saturating the Fc sites on the primary antibody. (ii) The first antibody was applied for a second time in place of the second antibody. This established that steric hindrance by the antibody and probe already present on the pili did not totally inhibit more labelling. (iii) The first antiserum and $5 \mathrm{~nm}$ gold probe were omitted to judge the affinity of the second antibody for the pili. (iv) The two antisera were used in the reverse order. (v) Finally, to ensure the absence of non-specific labelling by the probes, pili preparations were incubated with the probes only.

All the preparations were negatively stained with $1 \%(\mathrm{w} / \mathrm{v})$ ammonium molybdate $\mathrm{pH} 6.8$ containing $0.05 \%$ (w/v) BSA.

The dilutions of antisera and gold probe were made in $0.5 \mathrm{M}$-Tris buffer $\mathrm{pH} 7.4$ containing $1 \%(\mathrm{v} / \mathrm{v}) \mathrm{Tween} 20$, $1 \%(w / v)$ ovalbumin and $0 \cdot 1 \%(w / v)$ gelatin, and all incubations were at room temperature.

\section{RESULTS}

Immunogold labelling on pili was highly distinctive (Fig. 1a). The extent of labelling was easily seen since there were no bacterial structures similar in shape and density to the gold particles. Individual pili, decorated with antibody, could be recognized beneath the gold label. The gold labelling was distributed along the length of individual pili and pili bundles, and all the pili were labelled.

The labelling was highly specific. Non-specific background labelling in these preparations was so low that even very low levels of labelling associated with the pili could be identified with confidence (Fig. $1 b$ ). At very low levels of antibody labelling the gold particles were much easier to detect than the antibody molecules.

Negative controls, in which a non-reacting antibody was substituted for specific antibody in the labelling process, were very clean (Fig. 1c). Gold particles were almost absent and were on the background supporting film of the grid rather than on the pili.

Many of the bacterial strains examined possessed common somatic antigens. This was apparent when using unabsorbed antisera. Somatic labelling was independent of, and easily distinguished from, specific pilus labelling (Fig. $2 a$ ). In this example the heterologous antiserum labelled the bacterium heavily but did not label the pili. This could be distinguished from 

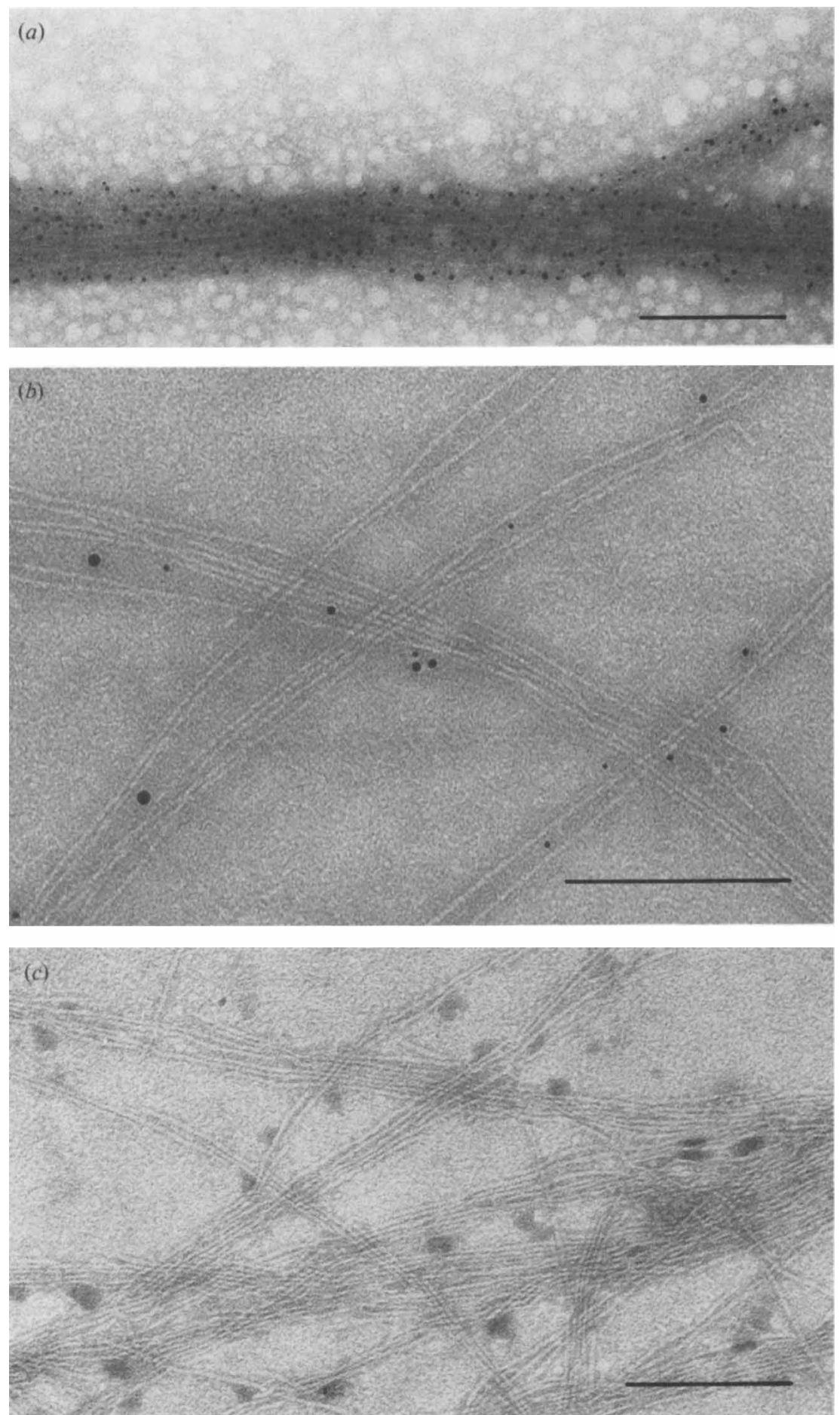

Fig. 1. (a) Strain 148 (serotype $\mathrm{H}$ ) pili labelled with homologous antiserum $\left(10^{-1}\right.$ dilution) and the $5 \mathrm{~nm}$ gold probe. The gold labelling is specific and highly distinctive. (b) Strain 215 (serotype B) pili labelled with a low concentration of homologous antiserum $\left(10^{-4}\right.$ dilution) and the $5 \mathrm{~nm}$ gold probe showing that very low levels of labelling can be detected. (c) Control preparation: pili of strain 215 (serotype B) incubated with antiserum ( $10^{-1}$ dilution) raised against strain 1045 (serotype $F$ ) and the $5 \mathrm{~nm}$ gold probe. The absence of labelling attests to the specificity of antiserum and gold probe. Bars, $0.2 \mu \mathrm{m}$. 

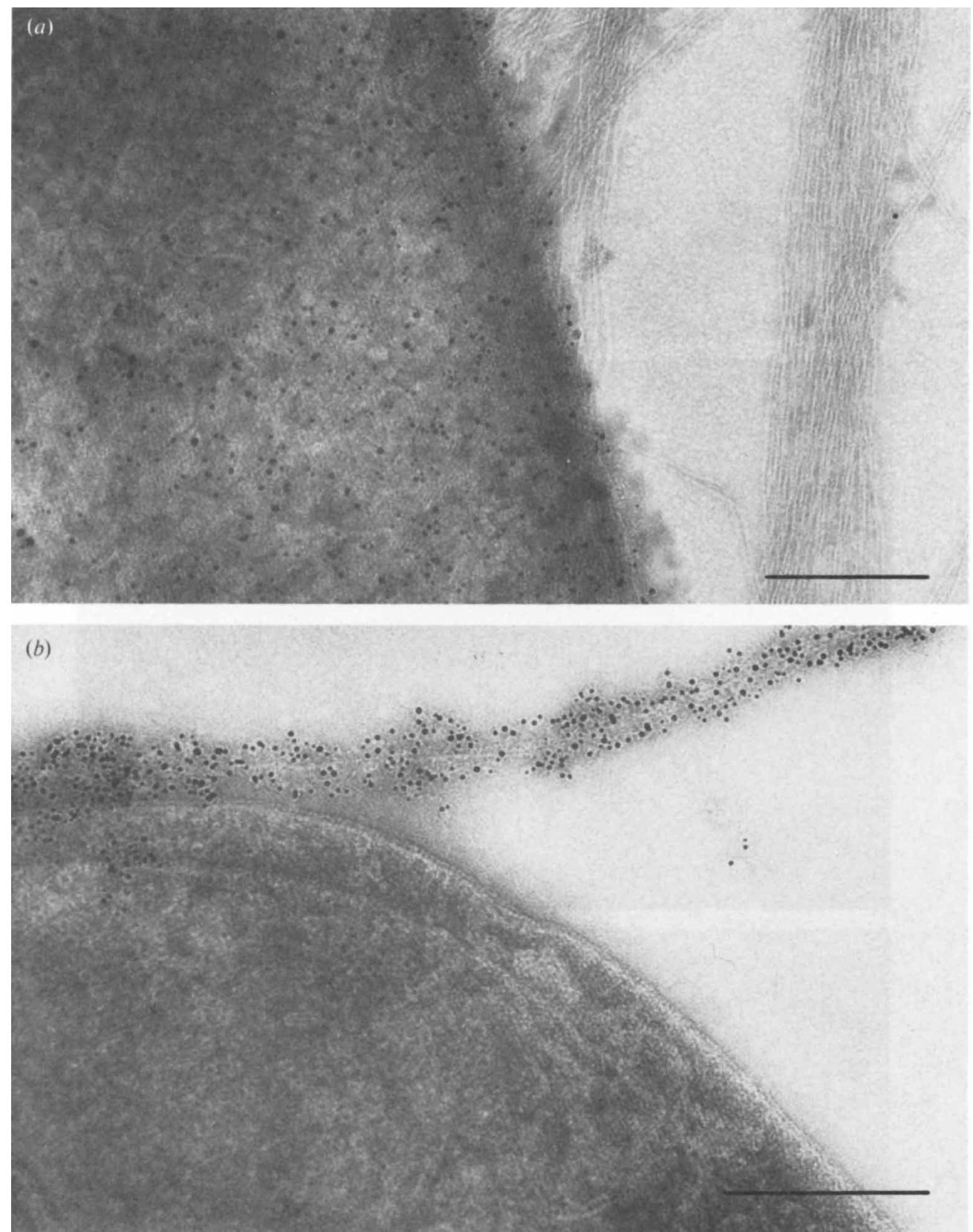

Fig. 2. (a) Strain 217 (serotype C) incubated with antiserum $\left(10^{-1}\right.$ dilution) raised against strain 215 (serotype B) and the $5 \mathrm{~nm}$ gold probe. The pili are not labelled although the cells show a positive reaction. (b) Strain 215 (serotype B) incubated with homologous antiserum $\left(10^{-1}\right.$ dilution) previously absorbed with bacterial strains 80200 (serotype N), 80116 (serotype K), 217 (serotype C) and 175 (serotype $\mathrm{G}$ ) and the $5 \mathrm{~nm}$ gold probe. Here the pili have been labelled but not the cells. Bars, $0 \cdot 2 \mu \mathrm{m}$.

examples using absorbed antisera where the sera labelled homologous pili but not the corresponding bacterial cells (Fig. $2 b$ ).

Older bacterial cultures contained a proportion of autolysed cells and their contents sometimes dispersed throughout the medium. Blebs of cytoplasm from the lysed cells were occasionally caught up with, or dried down on, the pili bundles. Any differences in the labelling 

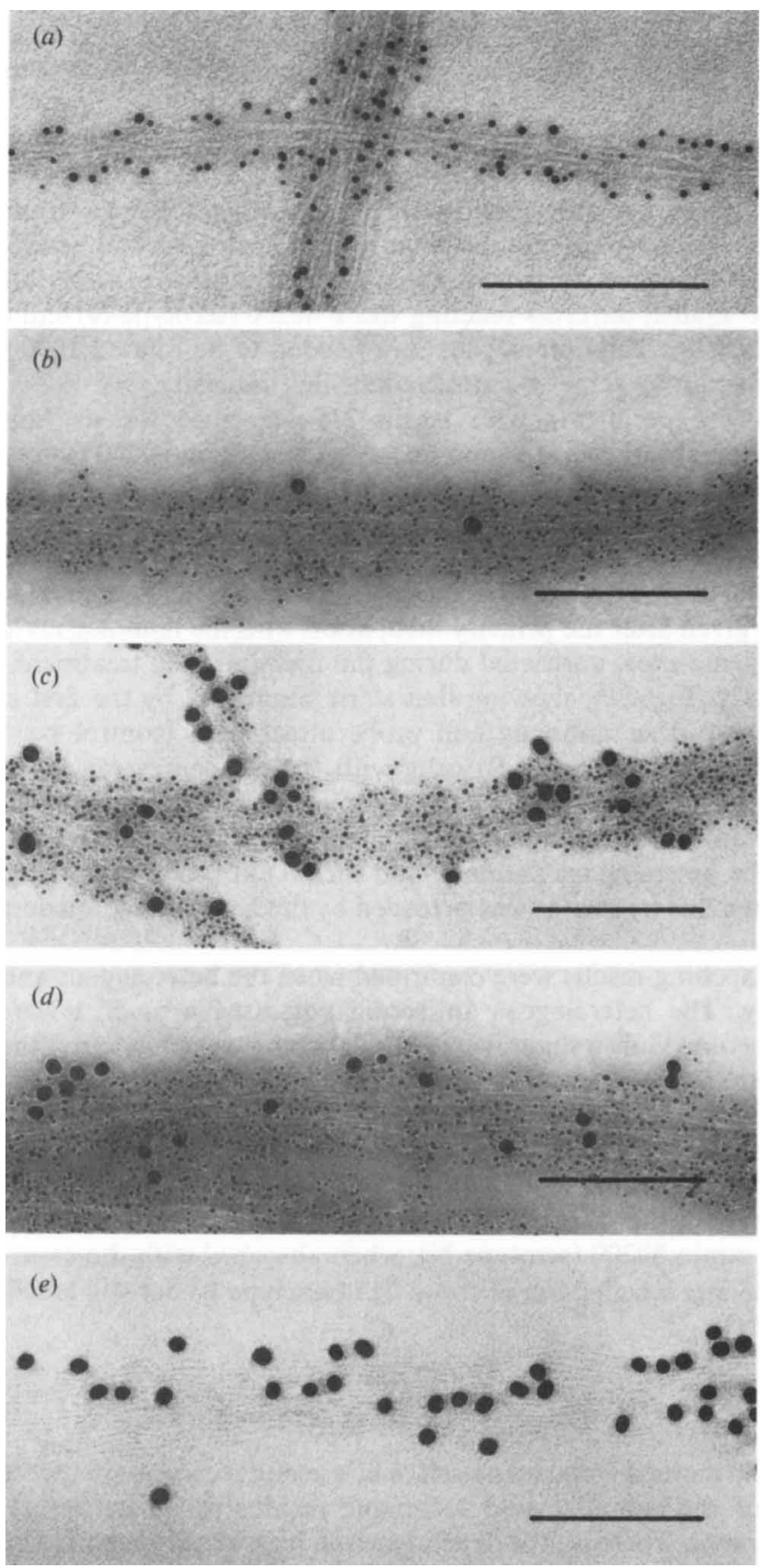

Fig. 3. (a) Strain 215 (serotype B) pili incubated with antiserum $\left(10^{-1}\right.$ dilution) raised against strain 80200 (serotype $\mathrm{N}$ ) and the $5 \mathrm{~nm}$ gold probe. This cross reaction did not occur with absorbed antiserum. $(b-e)$ Double labelling experiments showing distribution of antibodies (both at $10^{-1}$ dilution) raised against strain 80200 (serotype $\mathrm{N}$ ) and strain 215 (serotype B) on strain 215 (serotype B) pili. (b) Strain 215 (serotype B) pili labelled with homologous antibody and then the $5 \mathrm{~nm}$ probe followed by the $20 \mathrm{~nm}$ probe. The absence of the $20 \mathrm{~nm}$ probe indicates that the $5 \mathrm{~nm}$ probe has saturated most of the Fc sites on the antibody. (c) Strain 215 (serotype B) pili labelled with homologous antiserum, the $5 \mathrm{~nm}$ probe, a further incubation with homologous antiserum and then the $20 \mathrm{~nm}$ gold probe. The presence of the $20 \mathrm{~nm}$ probe indicates that steric hindrance by the initial antibody applied and the $5 \mathrm{~nm}$ probe does not totally prevent attachment of further antibody and probe. (d) Strain 215 (serotype B) pili labelled with homologous antiserum, the $5 \mathrm{~nm}$ gold probe, antiserum against strain 80200 (serotype $\mathrm{N}$ ) and the $20 \mathrm{~nm}$ gold probe. The presence of both probes shows that both antibodies have bound to the pili. (e) Strain 215 (serotype B) pili labelled with antiserum against strain 80200 (serotype $\mathrm{N}$ ) and the $20 \mathrm{~nm}$ gold probe showing higher binding of the antibody and gold probe than in $(d)$. This suggests that, in the double labelling experiment shown in $(d)$ steric hindrance by the first antibody and gold probe may have prevented some attachment of the second antibody and gold probe. Bars, $0.2 \mu \mathrm{m}$. 
characteristics between these blebs and pili could be detected clearly using the immunogold technique.

Absorbed antisera labelled only the homologous pili (Fig. $2 b$ ) indicating that the absorbing strains and the homologous strain possessed common somatic antigens.

An occasional unabsorbed antiserum labelled pili of a heterologous strain of $B$. nodosus (Fig. $3 a$ ). In one instance comparison was made between homologous and heterologous reactions by labelling pili (strain 215 , serotype B) with serial 10-fold dilutions of either homologous antibody or antibody raised against the cross-reacting strain 80200 (serotype $\mathrm{N}$ ) and then comparing the levels of pilus labelling. The homologous sera needed to be diluted 1000 -fold more than the heterologous antiserum to achieve a similar labelling intensity.

Double labelling experiments with strain 215 (serotype B), its homologous absorbed antiserum and the unabsorbed antiserum raised against strain 80200 (serotype $N$ ) showed that pili labelling with either antiserum was distributed along the length of all pili. The scant labelling with the $20 \mathrm{~nm}$ probe after the homologous antiserum and $5 \mathrm{~nm}$ probe [control (i), see Methods] showed that the $5 \mathrm{~nm}$ probe had saturated most of the available Fc sites on the antibody (Fig. 3b). However, if a second incubation with homologous antiserum followed by the $20 \mathrm{~nm}$ probe was given after the primary incubation with the homologous antiserum and $5 \mathrm{~nm}$ probe, more antigenic sites, unreacted during the first antibody treatment, were available for binding to antibody (Fig. $3 c$ ), showing that steric hindrance by the first antibody and probe would not prevent further antibody and probe attachment [control no. (ii), see Methods]. Treatment of strain 215 (serotype B) cells with the antiserum raised against strain 80200 (serotype $\mathrm{N}$ ) and the $20 \mathrm{~nm}$ probe after the homologous antiserum and $5 \mathrm{~nm}$ probe resulted in binding of 80200 antibodies throughout the length of the pilus bundles (Fig. $3 d$ ). Pili of cells incubated with the heterologous antibody and the $20 \mathrm{~nm}$ probe alone (Fig. $3 e$ ) showed more labelling than when this treatment was preceded by the homologous antiserum and $5 \mathrm{~nm}$ probe (Fig. 3d).

These double labelling results were confirmed when the heterologous antiserum was used as the first antibody. The heterologous antiserum possessed a much lower titre than did the homologous antiserum. Only a slight increase in labelling was found after the second incubation with this antiserum followed by the $20 \mathrm{~nm}$ probe (control no. ii). The $20 \mathrm{~nm}$ probe labelling in the double labelling incubation was more intense after the homologous antiserum than previously shown (Fig. $3 d$ ), reflecting the high titre of the homologous antibody but, as in the previous experiment, labelling was not as heavy as when the second antiserum was used alone and then labelled with the $20 \mathrm{~nm}$ probe.

Serum against strain 80200 (serotype N), when absorbed with the cross-reacting strain 215 (serotype B), no longer labelled pili of strain 215 (serotype B) but still labelled the pili of strain 80200 (serotype N).

\section{DISCUSSION}

The immunogold method has shown itself to be a useful technique in the study of pili antigens. The advantage of the colloidal gold technique resides in its particulate, very dense and distinctive appearance. There is little dependence on high quality negative staining as the results can be determined easily throughout a wide range of negative stain conditions.

The particulate nature of the gold probe enables individual pili to be seen beneath the marker. Somatic labelling can be distinguished readily from the pilus labelling, and the precise location of antigen on the pilus, the amount of labelling on each pilus and the percentage of pili labelling can be estimated with ease.

In contrast to other methods for measuring antibody, e.g. agglutination and complement fixation, the immunogold technique as used here does not permit the recognition of a welldefined end-point. With decreasing amounts of antibody the amount of labelling decreases until it is indistinguishable from the small, residual level of background labelling.

The easiest way of comparing titres of different antibody preparations is to compare labelling with 10-fold dilutions of the different antisera, expressing titres as the difference in the values of 
dilutions needed to achieve a similar intensity of labelling. In the examples studied the relative values agreed with the relative agglutination titres.

A further advantage of the colloidal gold marker is that it may be produced in different sizes, thus allowing for multiple labelling procedures.

The results from the double labelling experiments indicated that either the heterologous antiserum contained antibody identical with that of the homologous antiserum or that the heterologous antiserum contained antibody to a second, previously unrecognized pilus antigen. The lower level of labelling of $20 \mathrm{~nm}$ gold compared with the single labelling experiments indicates that steric hindrance reduces the amount of label.

In conclusion, the immunogold technique has been successfully applied to the immunocytochemical study of $B$. nodosus pili, all the labelling being carried out on suspensions of bacteria dried down onto electron microscope grids. The ease of detection of the immunocytochemical reactions should enable this technique to be used as a routine screening procedure for pilus antigens. It also possesses the potential for much wider applications for immunolabelling other antigens in suspension.

\section{REFERENCES}

Bendayan, M. (1982). Double immunocytochemical labelling applying the protein A-gold technique. Journal of Histochemistry and Cytochemistry 30, 8185.

Every, D. \& Skerman, T. M. (1982). Protection of sheep against experimental footrot by vaccination with pili purified from Bacteroides nodosus. New Zealand Veterinary Journal 30, 156-158.

EVERY, D. \& SkERMAN, T. M. (1983). Surface structure of Bacteroides nodosus in relation to virulence and immunoprotection in sheep. Journal of General Microbiology 129, 225-234.

GeUze, H., Slot, J., vaN DER Ley, P., SchefFer, R. \& GRIFFITH, J. (1981). Use of colloidal gold particles in double-labelling immuno-electron microscopy of ultrathin frozen tissue sections. Journal of Cell Biology 89, 653-665.

de Mey, J., Moeremans, M., Geuens, G., Nuydens, R. \& DE BRABANDER, M. (1981). High resolution light and electron microscopic localisation of tubulin with the IGS (immuno gold staining) method. Cell Biology International Reports 5, 889-899.

RoTH, J., Bendayan, M. \& ORCI, L. (1978). Ultrastructural localisation of antigens by the use of protein Agold complex. Journal of Histochemistry and Cytochemistry 26, 1074-1081.

Short, J. A., Thorley, C. M. \& Walker, P. D. (1976).
An electron microscope study of Bacteroides nodosus. Ultrastructure of organisms from primary isolates and different colony types. Journal of Applied Bacteriology 40, 311-315.

STEWART, D. J. (1975). Studies of morphology and antigenic structure of Fusiformis nodosus. Ph.D. thesis, University of Sydney, Australia.

STEWART, D. J. (1978). The role of various antigenic fractions of Bacteroides nodosus in eliciting protection against footrot in vaccinated sheep. Research in Veterinary Science 24, 14-19.

Stewart, D. J., Clark, B. L., Peterson, J. E., Griffiths, D. A. \& SMITH, E. F. (1982). Importance of pilus-associated antigen in Bacteroides nodosus vaccines. Research in Veterinary Science 32, 140 147.

Thorley, C. M. \& Egerton, J. R. (1981). Comparison of alum-absorbed or non-alum-absorbed oil emulsion vaccines containing either pilate or non-pilate Bacteroides nodosus cells in inducing and maintaining resistance of sheep to experimental footrot. Research in Veterinary Science 30, 32-37.

WALKer, P. D., ShORT, J., ThOMSON, R. O. \& RoBerTs, D. S. (1973). The fine structure of Fusiformis nodosus with special reference to the location of antigens associated with immunogenicity. Journal of General Microbiology 77, 351-361. 